\title{
Recent Updates on Vascular Complications in Patients with Type 2 Diabetes Mellitus
}

\author{
Chan-Hee Jung, Ji-Oh Mok
}

Division of Endocrinology and Metabolism, Department of Internal Medicine, Soonchunhyang University Bucheon Hospital, Soonchunhyang University College of Medicine, Bucheon, Korea

It is well known that patients with type 2 diabetes mellitus (T2DM) are at an increased risk of morbidity and mortality from atherosclerotic cardiovascular (CV) complications. Previously, the concept that diabetes mellitus (DM) is a "coronary artery disease (CAD) risk equivalent" was widely accepted, implying that all DM patients should receive intensive management. However, considerable evidence exist for wide heterogeneity in the risk of CV events among T2DM patients and the concept of a "CAD risk equivalent" has changed. Recent guidelines recommend further CV risk stratification in T2DM patients, with treatment tailored to the risk level. Although imaging modalities for atherosclerotic cardiovascular disease (ASCVD) have been used to improve risk prediction, there is currently no evidence that imaging-oriented therapy improves clinical outcomes. Therefore, controversy remains whether we should screen for CVD in asymptomatic T2DM. The coexistence of T2DM and heart failure (HF) is common. Based on recent CV outcome trials, sodium glucose cotransporter-2 inhibitors and glucagon like peptide-1 receptor agonists are recommended who have established ASCVD, indicators of high risk, or HF because of their demonstrated benefits for CVD. These circumstances have led to an increasing emphasis on ASCVD and HF in T2DM patients. In this review, we examine the literature published within the last 5 years on the risk assessment of CVD in asymptomatic T2DM patients. In particular, we review recent guidelines regarding screening for CVD and research focusing on the role of coronary artery calcium, coronary computed tomography angiography, and carotid intima-media thickness in asymptomatic T2DM patients.

Keywords: Atherosclerosis; Calcium; Coronary vessels; Carotid intima-media thickness; Risk assessment; Diabetes mellitus, type 2

\section{INTRODUCTION}

Type 2 diabetes mellitus (T2DM) has both microvascular and macrovascular complications [1]. The main cause of morbidity and mortality in T2DM is atherosclerotic cardiovascular disease (ASCVD), and patients with T2DM have a higher prevalence, extent, and severity of coronary artery disease (CAD) than those without T2DM [2,3]. The hormonal and physiological abnormalities associated with diabetes, including oxidative stress, in-

Received: 31 March 2020, Revised: 18 May 2020, Accepted: 5 June 2020 Corresponding author: $\mathrm{Ji}-\mathrm{Oh}$ Mok

Department of Internal Medicine, Soonchunhyang University Bucheon Hospital, Soonchunhyang University School of Medicine, 170 Jomaru-ro, Wonmi-gu, Bucheon 14584, Korea

Tel: +82-32-621-5156, Fax: +82-32-621-5016, E-mail: hanna@schmc.ac.kr sulin resistance, reactive oxygen generation, advanced glycation end products (AGEs), and increased inflammatory cytokine production, jointly promote ASCVD [4-6]. Variability in glucose levels and altered microRNA (miRNA) regulation have also been suggested as contributors to the pathogenesis of T2DM [7-10].

Diabetes mellitus (DM) was previously regarded as a "CAD risk equivalent" on the basis of the study by Haffner et al. [11], which reported a $20 \%$ increase in the 10 -year risk of adverse

Copyright $\odot 2020$ Korean Endocrine Society

This is an Open Access article distributed under the terms of the Creative Commons Attribution Non-Commercial License (https://creativecommons.org/ licenses/by-nc/4.0/) which permits unrestricted non-commercial use, distribution, and reproduction in any medium, provided the original work is properly cited. 
cardiovascular (CV) events for all DM patients. Since then, it has been recommended to treat all patients with DM as if they have CAD. However, numerous studies, including meta-analyses have reached different conclusions, suggesting that although DM is an important risk factor for the development of cardiovascular disease (CVD), it cannot be considered a "CAD risk equivalent" in all patients with DM $[12,13]$. In other words, T2DM patients may have a heterogeneous risk for CVD, so a different treatment strategy may be appropriate for patients with lower risk. Simultaneously, patients with evidence of subclinical CAD are at a much higher risk of CAD and such patients may be classified as being in a higher-risk group. Therefore, further stratification of patients improves the accuracy of the prediction of subclinical CAD and future CVD.

Controversy remains regarding the usefulness of systematic CVD screening in asymptomatic patients with T2DM for CV risk reclassification, and most guidelines do not recommend routine evaluation of asymptomatic patients with T2DM [14]. Nevertheless, noninvasive modalities for the detection of subclinical vascular disease, such as coronary artery calcium (CAC) scores and carotid intima-media thickness (IMT), are commonly used to estimate $\mathrm{CV}$ risk in real clinical practice.

Heart failure (HF) is another major cause of morbidity and mortality from CVD. The coexistence of T2DM and HF is frequent, but HF is often unrecognized in patients with T2DM [15]. Recent studies have found that two-fold higher rates of incident HF hospitalization in patients with T2DM than in those without T2DM [16]. The issue of HF in T2DM patients has attracted increasing interest from researchers and clinicians since recent $\mathrm{CV}$ outcome trials have highlighted the beneficial effects of sodium glucose cotransporter-2 (SGLT-2) inhibitors on HF in both T2DM patients with preexisting CVD and those with only CV risk factors [17].

Herein, we present an updated review of the pathogenesis of vascular complications and guidelines and modalities commonly used for risk stratification and screening of CVD in asymptomatic patients with T2DM.

\section{PATHOGENESIS OF VASCULAR}

\section{COMPLICATIONS IN T2DM}

It is well known that T2DM is associated with both macrovascular and microvascular complications [1]. Chronic hyperglycemia has been identified as the primary factor that contributes to the development of diabetic vascular complications [18]. Hyperglycemia causes endothelial dysfunction, which is the critical initiating factor in the pathogenesis of diabetic vascular complications [5]. Insulin resistance also plays an important role in the development of subclinical vascular disease associated with T2DM [19]. Although the mechanisms of T2DM-associated progression of atherosclerosis and vascular calcification are not fully understood, compelling evidence has emerged on the role of important drivers, including oxidative stress itself, activation of AGEs and receptors for AGEs, reduced nitric oxide bioavailability, increased formation of free radicals, inflammatory cytokine production, alterations in mineral metabolism, and the release of osteoprogenitor cells leading to inflammatory, fibrotic, and thrombotic processes (Fig. 1) [4,6,20,21]. In addition, recent studies have pointed out that specific miRNAs play a critical role in the development of diabetic vascular complications [10]. miRNAs are endogenous short, non-coding RNAs consisting of approximately 22 nucleotides that function to block protein translation and/or degrade their messenger RNA targets. They play a role in many processes related to cellular growth, angiogenesis, vascular repair, endothelial homeostasis, the modulation of progenitor cell function, metabolism, and immune response $[9,10]$. Patients with T2DM exhibit altered expression profiles of miRNAs [22]. In addition to poor glycemic control, glycemic fluctuation or variability also contributes to diabetic vascular complications $[7,8,23]$. A cross-sectional study by $\mathrm{Lu}$ et al. [24] investigated the association of time in range (TIR) obtained from continuous glucose monitoring (CGM) with carotid IMT in 2,215 patients with T2DM. In a fully adjusted model controlling for traditional risk factors of CVD, each $10 \%$ increase in TIR was associated with a $6.4 \%$ lower risk of abnormal carotid IMT. A prospective, multicenter, 5-year follow-up observational study is ongoing to investigate the relationships of glucose fluctuations evaluated by CGM using the FreeStyle Libre Pro (Abbott Diabetes Care, Alameda, CA, USA) with the incidence of composite CV events and the progression of atherosclerosis in T2DM patients without an apparent history of CVD [25].

\section{ASSESSMENT OF SUBCLINICAL ATHEROSCLEROSIS}

\section{CAC scores}

CAC scores have a strong correlation with the total coronary atherosclerotic burden and higher CAC scores are associated with higher event rates [26]. Patients with T2DM have a higher tendency for coronary artery calcification, and the prognostic significance of elevated CAC in predicting adverse events appears to be greater in patients with T2DM than in the general 


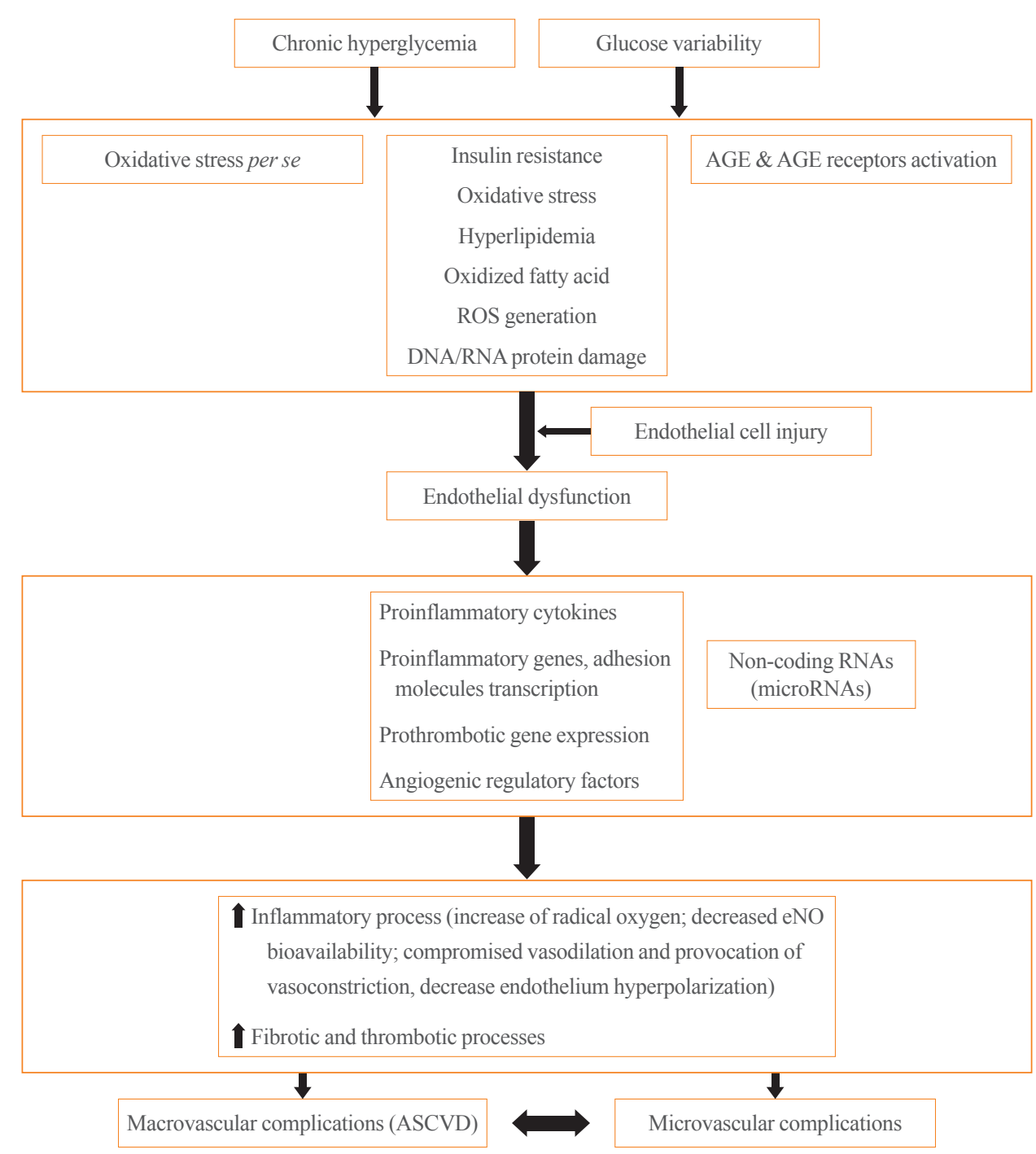

Fig. 1. Pathogenesis of atherosclerotic cardiovascular disease and vascular complications in type 2 diabetes mellitus. AGE, advanced glycation endproducts; ROS, reactive oxygen species; eNO, exhaled nitric oxide; ASCVD, atherosclerotic cardiovascular disease.

population. Nonetheless, several studies have shown that over $30 \%$ of patients with T2DM have no or very low evidence of coronary calcification $[27,28]$. A CAC score of 0 conferred a similar survival rate and low risk for CVD for patients with and without DM and a low event rate despite a high burden of risk factors. This phenomenon is referred to as the "power of zero." $\mathrm{CAC}$ is the best studied indicator of subclinical atherosclerosis due to its strong performance in risk stratification. Nevertheless, international guidelines still do not recommend routine use of the CAC score in risk stratification of patients with DM, due to remaining open questions regarding its cost-effectiveness, the negative consequences of the consequent radiation exposure, and the lack of a definite reducing in long-term $\mathrm{CV}$ events.

The mean duration of previous studies on the association of
CAC with the prognosis of T2DM patients was limited to 5 years (and most studies had a duration of less than 10 years) and data on the long-term predictive value of CAC are inadequate. Recently, long-term studies on whether CAC can predict adverse outcomes beyond 10 years of follow-up have been published (Table 1).

\section{Long-term clinical utility of CAC scores}

The CAC Consortium cohort is a multicenter cohort of 66,636 participants without coronary heart disease (CHD) who underwent CAC testing. The median follow-up duration was 12.5 years and the following five traditional risk factors were considered: (1) current cigarette smoking (10\%); (2) dyslipidemia (54\%); (3) DM (7\%); (4) hypertension (31\%); and (5) family 
Table 1. Representative Long-Term Cohort Studies of the Predictive Value of CAC

\begin{tabular}{|c|c|c|c|}
\hline Variable & CAC consortium (2019) & MESA (2019) & Observational study (2016) \\
\hline Age, yr & $54 \pm 11$ & $62 \pm 10$ & $53.4 \pm 10.5$ \\
\hline Total population & 66,636 & 6,814 & 9,715 \\
\hline Male sex, $\%$ & 67 & 47.2 & 59.3 \\
\hline $\mathrm{DM}, \%$ & 7 & 13 (11 for Chinese/5.3 for White) & 8.3 \\
\hline $\mathrm{HTN}, \%$ & 31 & 42 & 43.4 \\
\hline Dyslipidemia, $\%$ & 54 & 32 & 62.6 \\
\hline Race (Asian/White), \% & $4 / 89$ & 11.9 (mainly Chinese)/38.5 & - \\
\hline Duration of follow-up, yr & Median 12.5 & 11.1 & Median 14.7 \\
\hline CAC score $>0, \%$ & 55 & 57 for White, 50 for Chinese & 48.5/66.1 (non-DM/DM) \\
\hline Study outcome & $\begin{array}{l}\text { Cause-specific mortality (all-cause, non- } \\
\text { CVD, CVD, and CHD mortality) }\end{array}$ & Incident ASCVD & All-cause mortality \\
\hline Main findings & $\begin{array}{l}\text { HR of CHD and CVD mortality: } \\
\text { CAC scores } \geq 400 \text { vs. CAC of } 0: 5.44 \\
\text { and } 4.15 \text {, respectively. } \\
\text { Risk factors } \geq 3 \text { vs. without risk factors: } \\
2.09 \text { and } 1.84 \text {, respectively. } \\
\text { Participants with CAC scores } \geq 400 \text { and } \\
\text { no risk factors had significantly higher } \\
\text { all-cause, non-CVD, CVD, and CHD } \\
\text { mortality rates than participants with } \\
\geq 3 \text { risk factors and a CAC score of } 0 \text {. }\end{array}$ & $\begin{array}{l}\text { Ten-year ASCVD event rates increased } \\
\text { steadily across CAC categories re- } \\
\text { gardless of age, sex, or ethnicity. } \\
\text { While } 10 \text {-year event rates in those with } \\
\text { a CAC score of } 0 \text { were almost exclu- } \\
\text { sively below } 5 \% \text {, the rates in those } \\
\text { with a CAC score } \geq 100 \text { were above } \\
7.5 \% \text {. For each doubling of CAC, a } \\
14 \% \text { relative increment in ASCVD } \\
\text { risk was estimated. }\end{array}$ & $\begin{array}{l}\text { For a CAC score of } 0 \text {, the mortality rate } \\
\text { was similar between DM and non-DM } \\
\text { groups for the first } 5 \text { years. After } 5 \\
\text { years, the risk of mortality increased } \\
\text { significantly in the DM group, even in } \\
\text { those with a baseline CAC score of } 0 \text {. } \\
\text { The presence of CAC improved discrim- } \\
\text { ination and reclassification beyond } \\
\text { conventional risk factors. }\end{array}$ \\
\hline
\end{tabular}

CAC, coronary artery calcium; MESA, Multi-Ethnic Study of Atherosclerosis; DM, diabetes mellitus; HTN, hypertension; CVD, cardiovascular disease; CHD, coronary heart disease; ASCVD, atherosclerotic cardiovascular disease.

history of CHD (46\%) [29]. The study aimed to identify the prognostic value of a high CAC score among individuals without traditional risk factors and a CAC score of 0 among highrisk individuals. Across risk factor strata, $\mathrm{CAC}$ added prognostic information. For example, participants without traditional risk factors but with a $C A C \geq 400$ had significantly higher all-cause, non-CVD, CVD, and CHD mortality rates than participants with $\geq 3$ risk factors and a $\mathrm{CAC}$ of 0 . Across the spectrum of risk factor burden, higher CAC scores were strongly associated with long-term, all-cause mortality and a greater proportion of deaths due to CVD and CHD. The absence of CAC identified people with a low risk over 12 years of follow-up, with most deaths being non-CVD in nature, regardless of risk factor burden.

Very recently, another study of the CAC Consortium cohort has been published [30]. The long-term associations between no or minimal CAC and cause-specific mortality are currently unknown. Individuals with a CAC score of 0 (45\% prevalence, mean age 45 years) had stably low rates of CHD death, CVD death (ranging 0.32 to 0.43 per 1,000 person-years), and allcause death (1.38 to 1.62 per 1,000 person-years). Cancer was the predominant cause of death in this group, but the rates were also very low ( 0.47 to 0.79 per 1,000 person-years). Compared to those with a CAC score of 0 , individuals with a CAC score of 1 to 10 had an increased multivariable-adjusted risk of CVD death only under age 40 . Individuals with a CAC score $>10$ had multivariable-adjusted increased risks of CHD death, CVD death and all-cause death at all ages, and a higher proportion of CVD deaths. These findings support the emerging consensus that those with a CAC score of 0 represents a unique population with favorable all-cause prognosis who may be considered for more flexible treatment goals in primary prevention. Detection of any CAC, even a minimal score of 1 to 10 in young adults could be used to trigger aggressive preventive interventions.

The Multi-Ethnic Study of Atherosclerosis (MESA) study showed that CAC scores had significant long-term ( $>10$ years) value in prognosticating CVD in patients with metabolic syndrome and DM [27]. A CAC score of 0 was found at baseline in $37.3 \%$ of participants with DM, and was associated with an observed 10-year CHD event rate of only 3.7\% independent of DM duration, insulin use, or glycemic control. Based on this result, the authors suggested that the "warranty period" of a CAC score of 0 can be extended to 10 years from the previous dura- 
tion of around 5 years in those with DM.

Another observational study investigating the long-term predictive value of CAC scores for all-cause mortality in asymptomatic patients with T2DM was recently published [31]. In this 15-year cohort study, baseline CAC was determined in 9,715 individuals without DM and in 810 T2DM patients. In 34\% of the T2DM patients, the baseline CAC score was 0 . The cumulative mortality rate over 15 years according to the baseline CAC score was higher in the individuals with T2DM than in the nonDM group. A 15-year follow-up found that DM patients with a CAC score of 0 had a 2.5-fold higher hazard ratio (HR) for allcause mortality than their non-DM counterparts, although the annual mortality rates were still relatively low. Interestingly, a CAC score of 0 conferred a similar mortality rate in patients with and without T2DM for the first 5 years. After 5 years, however, the risk of mortality increased significantly for T2DM patients even in the presence of a baseline CAC score of 0 . A significant increase in mortality within the T2DM cohort began 5 years after the baseline normal CAC score. In contrast with the MESA study, this study suggests that the "warranty period" for a CAC score of 0 may be shorter for T2DM patients. The presence of CAC improved discrimination and reclassification beyond conventional risk factors in patients with T2DM. The authors stated that the mechanisms involved in the adverse prognosis after 5 years in patients with T2DM who had a CAC score of 0 were unclear, but may reflect a higher CAC progression rate in patients with T2DM than in those without T2DM. Another previous study by that research group reported that the warranty period of a CAC score of 0 converting from 0 to $>0$ occurred after 4 years in patients with T2DM [32]. It remains unclear whether a CAC of 0 in patients with T2DM is long-term warranty for CVD due to controversial results across long-term studies. A sub-analysis of patients with T2DM has not been reported in these studies.

\section{Progression of CAC}

Several studies have investigated the predictors of atherosclerosis progression and the impact of atherosclerosis progression on $\mathrm{CV}$ events in patients with T2DM. These studies have reported rates of atherosclerosis progression ranging from $8.8 \%$ to $29.6 \%$ during follow-up periods of about 2 years [33]. The determinants of progression of CAC in patients with T2DM have been established to be age, male sex, blood pressure, smoking, hyperlipidemia, waist-hip ratio, duration of DM, presence of retinopathy, statin use, white race, and Framingham risk score [33]. Other studies revealed that tight glycemic control could be im- portant in the progression of CAC or atherosclerosis [34,35], and many clinical risk factors could aggravate plaques in asymptomatic DM patients.

\section{Coronary computed tomography angiography}

Coronary computed tomography angiography (CCTA) can provide detailed information on atherosclerotic plaques in addition to coronary stenosis. CCTA can predict patients' outcome based on the presence, extent, and severity of CAD. A meta-analysis by Celeng et al. [36] evaluated the prognostic value of CCTA in 6,225 patients with T2DM with a follow-up period ranging from 20 to 66 months. The prevalence of obstructive CAD, nonobstructive CAD, and no CAD was $38 \%, 36 \%$, and $25 \%$, respectively. The annualized event rate was $17.1 \%$ for obstructive $\mathrm{CAD}, 4.5 \%$ for non-obstructive $\mathrm{CAD}$, and $0.1 \%$ for no CAD. Obstructive and non-obstructive CAD were associated with HRs of 5.4 and 4.2, respectively. A higher HR for obstructive $\mathrm{CAD}$ was observed in studies including revascularization than in those that did not (7.3 vs. $3.7, P=0.124)$. A more recent metaanalysis evaluated the predictive value of CCTA in asymptomatic patients with T2DM [37]. The analysis, which included 5,012 patients from 10 studies, showed that the presence of obstructive CAD on CCTA (vs. non-obstructive CAD or no CAD) was associated with a significantly elevated risk for adverse events (HR, 4.07; 95\% confidence interval [CI], 2.30 to 7.21). The estimated summary HR for non-obstructive plaque (vs. no CAD) was 2.17 (95\% CI, 1.11 to 4.25$)$. These results suggest that the presence and extent of CAD on CCTA are strong, independent predictors of $\mathrm{CV}$ events in asymptomatic patients with T2DM.

Although two previous randomized controlled trials (RCTs) $[38,39]$ failed to demonstrate that CCTA reduced the CV event rates in fewer than 1,000 patients with T2DM and short-term follow-up periods $<4$ years, observational studies $[40,41]$ showed promising results in the detection of subclinical CAD with CCTA. A prospective observational study by Lee et al. [40] investigated the efficacy of CCTA in predicting major adverse cardiovascular events (MACE) in asymptomatic T2DM patients and compared it with traditional risk factors during a mean follow-up period of 5.5 years. After adjusting for confounding risk factors, obstructive CAD remained an independent predictor of MACE (HR, 3.11; 95\% CI, 2.0 to 4.86). The performance of a risk prediction model based on $\mathrm{C}$-statistics was significantly improved (C-index, 0.788; 95\% CI, 0.747 to 0.829 ). In contrast, the risk prediction power of the $\mathrm{CAC}$ score remained unimproved (C-index, 0.740; $P=0.547)$. A 7-year population-based 
cohort study with 630 asymptomatic patients with T2DM revealed that CCTA provided additional prognostic information not obtainable from a clinical risk assessment and the CAC score alone [41].

In addition, a risk-score model for the assessment of CAD was suggested for use in asymptomatic DM patients [35]. The $\mathrm{CAD}$ risk score model was developed based on clinical risk factors for significant CAD (age, male sex, duration of DM, hypertension, current smoking, family history of premature $\mathrm{CAD}$, previous history of stroke, ratio of total cholesterol to high-density lipoprotein cholesterol, and neuropathy) and the scores ranged from 0 to 17. In total, 607 asymptomatic patients with T2DM were categorized into low-risk $(\leq 3)$, intermediate-risk (4 to 6 ), or high-risk ( $\geq 7)$ groups (for significant CAD on CCTA) according to model-based CAD risk estimates of $<20 \%, 20 \%$ to $50 \%$, or $>50 \%$. The low-risk ( $\leq 3$ ), intermediate-risk (4 to 6 ), and high-risk $(\geq 7)$ groups showed significant differences in the 5 -year cardiac event-free survival rate $(96.6 \% \pm 1.5 \%$ vs. $88.9 \% \pm$ $1.8 \%$ vs. $73.8 \% \pm 4.1 \%$, respectively) and the likelihood of CAD (12.6\% vs. $29.4 \%$ vs. $57.7 \%$, respectively) [35]. On the basis of this CAD risk-score model, the authors proposed that further evaluations for $\mathrm{CAD}$ are not recommended in low-risk patients, that CAC scoring may be appropriate as a screening test for intermediate-risk patients, and that CCTA might be considered as a first-line test for high-risk patients.

There are well-reviewed studies on subclinical CAD assessments by CCTA in asymptomatic patients with T2DM $[42,43]$, which can serve as a reference for further information.

Nonetheless, the prognostic value of CCTA in asymptomatic patients with T2DM is still debated. Moreover, limited data suggest that it would perform better than the CAC score [44]. Several studies have been conducted in low-to-intermediate-risk patients with suspected $\mathrm{CAD}$, wherein $<1.0 \%$ of patients with a CAC score of 0 had significant stenosis on CCTA. CCTA is generally not established as a screening tool for asymptomatic patients with T2DM. The latest European Association for the study of Diabetes (EASD)/European Society of Cardiology (ESC) guideline for detection and risk assessment of CAD states that CAC score and CCTA use "may be indicated" in asymptomatic patients with very high-risk (with a CAC score >400) [45]. Furthermore, the 2019 Korean Diabetes Association (KDA) guideline stated that CCTA may be indicated as screening tool on the basis of the meta-analysis mentioned above [46]. Nonetheless, current guidelines do not recommend CCTA for general screening in asymptomatic patients with T2DM. Further RCTs are needed.

\section{Carotid IMT}

Carotid artery disease is used as a surrogate marker of subclinical coronary atherosclerosis. The association between carotid IMT and CVD has been well established in both the general population and individuals with DM. A combined analysis of five longitudinal studies including 3,263 patients with DM, but without CVD, confirmed that the mean common carotid artery (CCA)-IMT (HR, 1.08 for every 0.1-mm increment; 95\% CI, 1.05 to 1.11 ), CCA-max-IMT (HR, 1.07 for every $0.1-\mathrm{mm}$ increment; 95\% CI, 1.04 to 1.10) and max-IMT (max-IMT in the CCA, bulb and internal carotid artery segments; HR, 1.08 for every $0.1-\mathrm{mm}$ increment; $95 \% \mathrm{CI}, 1.05$ to 1.11 ,) at baseline could be predictors for the development of CVD [47]. A cohort study with a median follow-up of 10.8 years evaluated the predictive capacity of carotid IMT and plaques for CV outcomes and microvascular complications in 478 patients with T2DM [48]. Individuals with a higher carotid IMT and plaques had a 1.5- to 1.8-fold increased risk of $\mathrm{CV}$ events and a 1.6-fold higher risk of renal outcomes. The assessment of the carotid IMT and plaques modestly improved CV risk discrimination over classic risk factors.

Compared with other methods of evaluating the coronary anatomy, carotid IMT testing via B-mode ultrasonography has several advantages. Carotid IMT measurements are noninvasive, safe, simple, and relatively inexpensive and can be repeatedly and reproducibly performed with no adverse effects. These benefits make it easy for physicians to use carotid IMT in clinical practice when making decisions. Nevertheless, there are some controversial points regarding the choice of carotid ultrasound parameters. For instance, which carotid ultrasound parameters should be measured? Choices include carotid IMT or plaque, carotid IMT including plaque or carotid IMT not including plaque, the CCA segment or bulb and internal carotid artery, and the mean carotid IMT or maximum carotid IMT. Regarding the measurement of carotid IMT or plaque, several studies have shown that measurements of carotid plaque are more useful than carotid IMT for predicting CVD. A cohort of 262 asymptomatic patients with T2DM showed that carotid plaque was more predictive of a non- 0 CAC score and severe CAC burden than carotid IMT in asymptomatic T2DM patients [49]. Akazawa et al. [50] showed that combining carotid plaque with carotid IMT yielded a much superior screening method for detecting CAD by multi-detector computed tomography in asymptomatic patients with T2DM. Another multicenter, observational, prospective study included 259 asymptomatic patients with T2DM who were followed-up for 34 months after measurements of ca- 
rotid IMT and carotid plaque, and CAD assessments with CCTA [51]. Patients with carotid plaque showed a higher incidence of MACE than those with patients with no carotid plaque. Therefore, carotid plaque assessment in addition to carotid IMT should be considered. The greatest weakness of carotid IMT is the lack of standardized protocols. In addition, patients' age must be taken into consideration when interpreting carotid IMT results.

In summary, although extensive evidence has been presented that the role of carotid IMT and/or plaque in addition to traditional CV risk factors significantly improve the prediction of the occurrence of CVD, controversy remains due to the several above-mentioned limitations and the lack of sufficient evidence regarding improvements in $\mathrm{CV}$ outcomes.

\section{CAC versus CCTA, versus carotid IMT}

Ninety-eight asymptomatic patients with T2DM without known CVD underwent CAC score, CCTA, carotid ultrasonography, and exercise treadmill testing [44]. The researchers found that $56 \%$ had no CAD by CCTA. Among these tests, the CAC score had the highest sensitivity and specificity for predicting CAD.

\section{GUIDELINES: RECENT UPDATES REGARDING SCREENING FOR CV RISK IN T2DM PATIENTS}

\section{American Diabetes Association}

In the 2020 American Diabetes Association (ADA) standards of medical care [14], routine screening for CAD is not recommended in asymptomatic patients with high ASCVD risk, as it does not improve $\mathrm{CV}$ outcomes if all risk factors are already intensively managed. While the CAC score may improve CV risk assessment, the role of the CAC score beyond risk stratification remains unclear. Therefore, the benefit of screening asymptomatic T2DM patients by CAC score is controversial, although research is ongoing. Candidates for advanced or invasive cardiac testing include those with typical or atypical cardiac symptoms and an abnormal resting electrocardiogram (ECG), in whom exercise ECG testing may be performed as the initial test (Table 2).

\section{The ESC/EASD}

In the $2019 \mathrm{ESC} / \mathrm{EASD}$ guideline [45], routine screening for CAD in asymptomatic T2DM is not recommended. However, stress testing or CCTA may be indicated in very high-risk asymptomatic individuals (with peripheral arterial disease, a high CAC score, proteinuria, or renal failure). The ESC classified
CV risk levels in T2DM patients as follows: a very-high-risk group of patients with T2DM and established CVD or other target organ damage (TOD) (proteinuria, renal impairment defined as eGFR $<30 \mathrm{~mL} / \mathrm{min} / 1.72 \mathrm{~m}^{2}$, left ventricular hypertrophy or retinopathy), or three or more major risk factors (age, hypertension, dyslipidemia, smoking, obesity); a high-risk group of patients with $\mathrm{T} 2 \mathrm{DM}$ duration $\geq 10$ years without TOD plus any other additional risk factor; and a moderate-risk group of young patients aged $<50$ years with a T2DM duration $<10$ years without other risk factors. The routine assessment of microalbuminuria is indicated to identify patients at risk of developing renal dysfunction or at high risk of future CVD (class I, level B). A resting ECG is indicated in patients with DM diagnosed with hypertension or with suspected CVD (class I, level C). An assessment of the carotid and/or femoral plaque burden with arterial ultrasonography should be considered as a risk modifier in asymptomatic patients with DM (class IIa, level B). The CAC score with computed tomography may be considered as a risk modifier in the $\mathrm{CV}$ risk assessment of asymptomatic patients with DM at moderate risk (class IIa, level B). In addition, carotid IMT screening for CV risk assessment is not recommended because carotid IMT has not shown incremental value over the CAC score for predicting CVD (class III, level A).

\section{American Association of Clinical Endocrinologists (AACE)/ American College of Endocrinology (ACE)}

In this clinical practice guideline for the prevention of CVD, it is stated that CAC measurements have been shown to be of high predictive value and are useful in refining risk stratification to determine the need for more aggressive treatment strategies (grade B; best evidence level [BEL] 2). In this guideline, recommendations are assigned grades that map to the BEL ratings based on the highest-quality supporting evidence level. The recommendation grades are designated as " $\mathrm{A}=$ strong, $\mathrm{B}=$ intermediate, $\mathrm{C}=$ weak, or $\mathrm{D}=$ only expert opinion or a lack of conclusive scientific evidence." Briefly, there are four intuitive levels of evidence: $1=$ strong, 2 =intermediate, $3=$ weak, and $4=$ no evidence. Carotid IMT may be considered to refine risk stratification to determine the need for more aggressive ASCVD preventive strategies (grade B; BEL 2) [52].

\section{American College of Cardiology (ACC)/American Heart Association (AHA) guideline on the primary prevention of CVD}

The 2019 ACC/AHA guideline recommended CAC testing in selected candidates who might benefit from knowing their CAC 
Table 2. Recent Guidelines on Screening for CVD in Asymptomatic Patients with Type 2 Diabetes Mellitus

\begin{tabular}{|c|c|c|}
\hline Professional organization & Screening asymptomatic patients & Further consideration \\
\hline $\begin{array}{l}\text { American Diabetes Association } \\
(2020)\end{array}$ & $\begin{array}{l}\text { Routine screening for CAD is not } \\
\text { recommended in asymptomatic patients } \\
\text { with high ASCVD risk, in case these high- } \\
\text { risk patients should already be receiving } \\
\text { intensive medical therapy. }\end{array}$ & $\begin{array}{l}\text { Exercise ECG testing may be used as the initial test in case of } \\
\text { typical or atypical cardiac symptom and abnormal resting ECG. } \\
\text { Regarding CAC, in patients with above } 40 \text { years of age, its } \\
\text { measurement is reasonable for CV risk assessment. However, the } \\
\text { role of CAC beyond risk stratification in not clear, so routine use is } \\
\text { not recommended. }\end{array}$ \\
\hline $\begin{array}{l}\text { European Association for the } \\
\text { Study of Diabetes/European } \\
\text { Society of Cardiology (2019) }\end{array}$ & $\begin{array}{l}\text { Routine screening for CAD is not } \\
\text { recommended. }\end{array}$ & $\begin{array}{l}\text { Stress testing or CCTA may be indicated in very high-risk } \\
\text { asymptomatic patients (peripheral artery disease, high CAC score, } \\
\text { proteinuria, or renal failure). } \\
\text { CAC score may be considered as a risk modifier in asymptomatic } \\
\text { patients. } \\
\text { Carotid plaque burden should be considered as a risk modifier, but } \\
\text { carotid IMT is not recommended. }\end{array}$ \\
\hline $\begin{array}{l}\text { American College of Cardiology/ } \\
\text { American Heart Association } \\
\text { (2019) }\end{array}$ & $\begin{array}{l}\text { Screening may be useful in selected } \\
\text { patients. }\end{array}$ & $\begin{array}{l}\text { CAC can be recommended in selected patients; those who are } \\
\text { reluctant or concerned about restarting statins, or whether there is } \\
\text { benefit or not regarding statin therapy, and with factors that increase } \\
\text { their ASCVD risk, although they are in a borderline risk group }\end{array}$ \\
\hline $\begin{array}{l}\text { American Association of Clinical } \\
\text { Endocrinologist/American } \\
\text { College of Endocrinology } \\
\text { (2017) }\end{array}$ & $\begin{array}{l}\text { CAC is useful in refining risk stratification } \\
\text { to determine the need for more aggressive } \\
\text { treatment strategies due to its high predic- } \\
\text { tive value. } \\
\text { Carotid IMT may be considered to refine } \\
\text { risk stratification. }\end{array}$ & \\
\hline Korean Diabetes Association & $\begin{array}{l}\text { Screening for CAD is not recommended if } \\
\text { patients are asymptomatic and their } \mathrm{CV} \\
\text { risk factors are already well controlled. }\end{array}$ & $\begin{array}{l}\text { Exercise ECG test as the first screening may be considered if atypical } \\
\text { symptoms such as unexplainable dyspnea, chest discomfort, related } \\
\text { vascular symptom or signs (carotid artery bruit, transient ischemic } \\
\text { attack, claudication, stroke, peripheral artery disease, Q wave on } \\
\text { ECG), high CAC score, and proteinuria are present (expert } \\
\text { recommendation, class IIb). } \\
\text { CAC score may be screened in patients } \geq 40 \text { years for CV. }\end{array}$ \\
\hline
\end{tabular}

CVD, cardiovascular disease; CAD, coronary artery disease; ASCVD, atherosclerotic cardiovascular disease; ECG, electrocardiogram; CAC, coronary artery calcium; CV, cardiovascular; CCTA, coronary computed tomography angiography; IMT, intima-media thickness.

score is 0 , as follows: patients reluctant to initiate statin who wish to understand their risk and potential for benefit more precisely; patients concerned about the need to reinstitute statin therapy after discontinuation for statin-associated symptoms; older patients (men 55 to 80 years of age; women 60 to 80 years of age) with a low burden of risk factors who question whether they would benefit from statin therapy; and middle-aged adults (40 to 55 years of age) with a pooled cohort equations-calculated 10 -year risk for ASCVD of 5\% to $<7.5 \%$ and factors that increase their ASCVD risk, although they are in a borderline risk group [53].

\section{The KDA}

In the 2019 KDA treatment guideline for DM, screening for $\mathrm{CAD}$ is not recommended if patients are asymptomatic and their CV risk factors are already well controlled (evidence A, class III) [46]. Screening may be considered if atypical symptoms such as unexplainable dyspnea, chest discomfort, related vascular symptoms or signs (carotid artery bruit, transient ischemic attack, claudication, stroke, peripheral artery disease, Q wave on ECG), a high CAC score, and proteinuria are present (expert recommendation, class IIb). An exercise ECG test may be regarded as the first screening test if patients have no symptoms and few $\mathrm{CV}$ risk factors (expert recommendation, class IIb). The CAC score may be determined in patients $\geq 40$ years for risk assessment of $\mathrm{CV}$.

\section{HEART FAILURE}

A recent large observational study of 271,174 patients with T2DM registered in the Swedish National Diabetes Register suggested that the optimal management of conventional $\mathrm{CV}$ risk 
factors (glycated hemoglobin, blood pressure, low-density lipoprotein cholesterol, albuminuria, and smoking) within the target ranges may offset the excess risk of ASCVD such as myocardial infarction and stroke, but be ineffective in reducing the risk of HF [54]. The risk of hospitalization for HF was consistently higher among patients with T2DM who had no additional risk factors outside the target ranges than among controls (HR, 1.45; 95\% CI, 1.34 to 1.57). Recent CV outcomes trials of SGLT-2 inhibitors have provided robust data supporting the role of these drugs in the primary prevention of HF in patients with T2DM. Based on these results, multiple clinical trials about their effects of SGLT-2 inhibitors on HF in patients without T2DM are ongoing [55].

T2DM was associated with a two- to four-fold increased risk of HF [56]. Patients with asymptomatic HF often have subclinical abnormalities of cardiac structure and function and any of these abnormalities is associated with an increased risk of symptomatic HF and death.

In light of the prognostic implications of concurrent T2DM and HF, the development of screening strategies for unrecognized HF among patients with T2DM is important. Nevertheless, since screening strategies for HF are sparse in patients with T2DM, current screening for HF might be based on clinical characteristics [57]. Although symptoms are often non-specific, a detailed history should always be obtained. Information should be elicited about typical symptoms, such as shortness of breath, orthopnea, paroxysmal nocturnal dyspnea, reduced exercise tolerance, and ankle edema. The plasma concentration of natriuretic peptides (NPs) can be used as an initial diagnostic test and is recommended for ruling-out HF. In 2017, for the first time, the ACC/AHA/Heart Failure Society of America HF management guidelines issued a class IIA recommendation for NPs (BNP and NT-proBNP) screening for those at risk of developing HF [58]. Elevated NP levels help establish an initial working diagnosis, identifying those who require further cardiac investigation and echocardiography. In addition, HF is unlikely in patients presenting with a completely normal ECG. Therefore, the routine use of an ECG is mainly recommended to rule out HF.

\section{CONCLUSIONS}

Extensive efforts are made to control CV risk factors and to reduce CV complications in patients with T2DM. In addition, new hypoglycemic agents have provided significant benefits for reducing $\mathrm{CV}$ events and hospitalization due to $\mathrm{HF}$ in recent clinical trials. Nonetheless, ASCVD is still the main cause of morbidity and mortality in patients with T2DM. Several CV imaging modalities for atherosclerosis have been employed to improve risk stratification and event prediction. Among them, the CAC score is the most widely studied and is considered to be the most promising screening tool by international organizations. However, to date there is no clear evidence that screening using imaging modalities reduces $\mathrm{CV}$ events and improves clinical outcomes in asymptomatic patients with T2DM.

\section{CONFLICTS OF INTEREST}

No potential conflict of interest relevant to this article was reported.

\section{ACKNOWLEDGMENTS}

This study was funded by a grant from Soonchunhyang University.

\section{ORCID}

Chan-Hee Jung https://orcid.org/0000-0001-8988-0187

Ji-Oh Mok https://orcid.org/0000-0003-4882-1206

\section{REFERENCES}

1. Fowler MJ. Microvascular and macrovascular complications of diabetes. Clin Diabetes 2008;26:77-82.

2. Grundy SM, Benjamin IJ, Burke GL, Chait A, Eckel RH, Howard BV, et al. Diabetes and cardiovascular disease: a statement for healthcare professionals from the American Heart Association. Circulation 1999;100:1134-46.

3. Gu K, Cowie CC, Harris MI. Mortality in adults with and without diabetes in a national cohort of the U.S. population, 1971-1993. Diabetes Care 1998;21:1138-45.

4. Bessueille L, Magne D. Inflammation: a culprit for vascular calcification in atherosclerosis and diabetes. Cell Mol Life Sci 2015;72:2475-89.

5. Shi Y, Vanhoutte PM. Macro- and microvascular endothelial dysfunction in diabetes. J Diabetes 2017;9:434-49.

6. Rhee SY, Kim YS. The role of advanced glycation end products in diabetic vascular complications. Diabetes Metab J 2018;42:188-195.

7. Xia J, Yin C. Glucose variability and coronary artery disease. Heart Lung Circ 2019;28:553-9.

8. Liang S, Yin H, Wei C, Xie L, He H, Liu X. Glucose vari- 
ability for cardiovascular risk factors in type 2 diabetes: a meta-analysis. J Diabetes Metab Disord 2017;16:45.

9. McClelland AD, Kantharidis P. microRNA in the development of diabetic complications. Clin Sci (Lond) 2014;126: 95-110.

10. Banerjee J, Nema V, Dhas Y, Mishra N. Role of microRNAs in type 2 diabetes and associated vascular complications. Biochimie 2017;139:9-19.

11. Haffner SM, Lehto S, Ronnemaa T, Pyorala K, Laakso M. Mortality from coronary heart disease in subjects with type 2 diabetes and in nondiabetic subjects with and without prior myocardial infarction. N Engl J Med 1998;339:229-34.

12. Bulugahapitiya U, Siyambalapitiya S, Sithole J, Idris I. Is diabetes a coronary risk equivalent? Systematic review and meta-analysis. Diabet Med 2009;26:142-8.

13. Rana JS, Liu JY, Moffet HH, Jaffe M, Karter AJ. Diabetes and prior coronary heart disease are not necessarily risk equivalent for future coronary heart disease events. J Gen Intern Med 2016;31:387-93.

14. American Diabetes Association. 10. Cardiovascular disease and risk management: standards of medical care in diabetes-2020. Diabetes Care 2020;43:S111-34.

15. Cavender MA, Steg PG, Smith SC Jr, Eagle K, Ohman EM, Goto $\mathrm{S}$, et al. Impact of diabetes mellitus on hospitalization for heart failure, cardiovascular events, and death: outcomes at 4 years from the reduction of atherothrombosis for continued health (REACH) registry. Circulation 2015;132:923-31.

16. McAllister DA, Read SH, Kerssens J, Livingstone S, McGurnaghan S, Jhund P, et al. Incidence of hospitalization for heart failure and case-fatality among 3.25 million people with and without diabetes mellitus. Circulation 2018;138: 2774-86.

17. Liu Y, Gao G, Yang C, Zhou K, Shen B, Liang H, et al. The role of circulating microRNA-126 (miR-126): a novel biomarker for screening prediabetes and newly diagnosed type 2 diabetes mellitus. Int J Mol Sci 2014;15:10567-77.

18. Zelniker TA, Wiviott SD, Raz I, Im K, Goodrich EL, Bonaca MP, et al. SGLT2 inhibitors for primary and secondary prevention of cardiovascular and renal outcomes in type 2 diabetes: a systematic review and meta-analysis of cardiovascular outcome trials. Lancet 2019;393:31-9.

19. Forbes JM, Fotheringham AK. Vascular complications in diabetes: old messages, new thoughts. Diabetologia 2017; 60:2129-38.

20. Paneni F, Beckman JA, Creager MA, Cosentino F. Diabetes and vascular disease: pathophysiology, clinical consequenc- es, and medical therapy: part I. Eur Heart J 2013;34:2436-43.

21. Yahagi K, Kolodgie FD, Lutter C, Mori H, Romero ME, Finn AV, et al. Pathology of human coronary and carotid artery atherosclerosis and vascular calcification in diabetes mellitus. Arterioscler Thromb Vasc Biol 2017;37:191-204.

22. Pereira CA, Carneiro FS, Matsumoto T, Tostes RC. Bonus effects of antidiabetic drugs: possible beneficial effects on endothelial dysfunction, vascular inflammation and atherosclerosis. Basic Clin Pharmacol Toxicol 2018;123:523-38.

23. Zhang ZY, Miao LF, Qian LL, Wang N, Qi MM, Zhang YM, et al. Molecular mechanisms of glucose fluctuations on diabetic complications. Front Endocrinol (Lausanne) 2019; 10:640

24. Lu J, Ma X, Shen Y, Wu Q, Wang R, Zhang L, et al. Time in range is associated with carotid intima-media thickness in type 2 diabetes. Diabetes Technol Ther 2020;22:72-8.

25. Mita T, Katakami N, Okada Y, Yoshii H, Osonoi T, Nishida $\mathrm{K}$, et al. Protocol of a prospective observational study on the relationship between glucose fluctuation and cardiovascular events in patients with type 2 diabetes. Diabetes Ther 2019; 10:1565-75.

26. Rumberger JA, Simons DB, Fitzpatrick LA, Sheedy PF, Schwartz RS. Coronary artery calcium area by electronbeam computed tomography and coronary atherosclerotic plaque area: a histopathologic correlative study. Circulation 1995;92:2157-62.

27. Yeboah J, Erbel R, Delaney JC, Nance R, Guo M, Bertoni AG, et al. Development of a new diabetes risk prediction tool for incident coronary heart disease events: the MultiEthnic Study of Atherosclerosis and the Heinz Nixdorf Recall Study. Atherosclerosis 2014;236:411-7.

28. Raggi P, Shaw LJ, Berman DS, Callister TQ. Prognostic value of coronary artery calcium screening in subjects with and without diabetes. J Am Coll Cardiol 2004;43:1663-9.

29. Grandhi GR, Mirbolouk M, Dardari ZA, Al-Mallah MH, Rumberger JA, Shaw LJ, et al. Interplay of coronary artery calcium and risk factors for predicting CVD/CHD mortality: the CAC consortium. JACC Cardiovasc Imaging 2020;13: 1175-86.

30. Blaha MJ, Cainzos-Achirica M, Dardari Z, Blankstein R, Shaw LJ, Rozanski A, et al. All-cause and cause-specific mortality in individuals with zero and minimal coronary artery calcium: a long-term, competing risk analysis in the Coronary Artery Calcium Consortium. Atherosclerosis 2020; 294:72-9.

31. Valenti V, Hartaigh BO, Cho I, Schulman-Marcus J, Gransar 
H, Heo R, et al. Absence of coronary artery calcium identifies asymptomatic diabetic individuals at low near-term but not long-term risk of mortality: a 15-year follow-up study of 9715 patients. Circ Cardiovasc Imaging 2016;9:e003528.

32. Min JK, Lin FY, Gidseg DS, Weinsaft JW, Berman DS, Shaw LJ, et al. Determinants of coronary calcium conversion among patients with a normal coronary calcium scan: what is the "warranty period" for remaining normal? J Am Coll Cardiol 2010;55:1110-7.

33. Min JK, Lin FY, Gidseg DS, Weinsaft JW, Berman DS, Shaw LJ, et al. Determinants of coronary calcium conversion among patients with a normal coronary calcium scan: what is the "warranty period" for remaining normal? J Am Coll Cardiol 2010;55:1110-7.

34. Kataoka Y, Yasuda S, Miyamoto Y, Sase K, Kosuge M, Kimura K, et al. Effects of voglibose and nateglinide on glycemic status and coronary atherosclerosis in early-stage diabetic patients. Circ J 2012;76:712-20.

35. Park GM, An H, Lee SW, Cho YR, Gil EH, Her SH, et al. Risk score model for the assessment of coronary artery disease in asymptomatic patients with type 2 diabetes. Medicine (Baltimore) 2015;94:e508.

36. Celeng C, Maurovich-Horvat P, Ghoshhajra BB, Merkely B, Leiner T, Takx RA. Prognostic value of coronary computed tomography angiography in patients with diabetes: a metaanalysis. Diabetes Care 2016;39:1274-80.

37. Beller E, Meinel FG, Schoeppe F, Kunz WG, Thierfelder KM, Hausleiter J, et al. Predictive value of coronary computed tomography angiography in asymptomatic individuals with diabetes mellitus: systematic review and meta-analysis. J Cardiovasc Comput Tomogr 2018;12:320-8.

38. Muhlestein JB, Lappe DL, Lima JA, Rosen BD, May HT, Knight $\mathrm{S}$, et al. Effect of screening for coronary artery disease using CT angiography on mortality and cardiac events in high-risk patients with diabetes: the FACTOR-64 randomized clinical trial. JAMA 2014;312:2234-43.

39. Turrini F, Scarlini S, Mannucci C, Messora R, Giovanardi P, Magnavacchi $\mathrm{P}$, et al. Does coronary atherosclerosis deserve to be diagnosed early in diabetic patients? The DADDY-D trial. Screening diabetic patients for unknown coronary disease. Eur J Intern Med 2015;26:407-13.

40. Lee KY, Hwang BH, Kim TH, Kim CJ, Kim JJ, Choo EH, et al. Computed tomography angiography images of coronary artery stenosis provide a better prediction of risk than traditional risk factors in asymptomatic individuals with type 2 diabetes: a long-term study of clinical outcomes. Dia- betes Care 2017;40:1241-8.

41. Halon DA, Azencot M, Rubinshtein R, Zafrir B, Flugelman MY, Lewis BS. Coronary computed tomography (CT) angiography as a predictor of cardiac and noncardiac vascular events in asymptomatic type 2 diabetics: a 7-year population-based cohort study. J Am Heart Assoc 2016;5:e003226.

42. Guaricci AI, De Santis D, Carbone M, Muscogiuri G, Guglielmo M, Baggiano A, et al. Coronary atherosclerosis assessment by coronary $\mathrm{CT}$ angiography in asymptomatic diabetic population: a critical systematic review of the literature and future perspectives. Biomed Res Int 2018;2018:8927281.

43. Lee CH, Lee SW, Park SW. Diabetes and subclinical coronary atherosclerosis. Diabetes Metab J 2018;42:355-63.

44. Rassi CH, Churchill TW, Tavares CA, Fahel MG, Rassi FP, Uchida $\mathrm{AH}$, et al. Use of imaging and clinical data to screen for cardiovascular disease in asymptomatic diabetics. Cardiovasc Diabetol 2016;15:28.

45. Cosentino F, Grant PJ, Aboyans V, Bailey CJ, Ceriello A, Delgado V, et al. 2019 ESC guidelines on diabetes, pre-diabetes, and cardiovascular diseases developed in collaboration with the EASD. Eur Heart J 2020;41:255-323.

46. Korean Diabetes Association. Korean 2019 treatment guideline for diabetes [Internet]. Seoul: Korean Diabetes Association; 2019 [cited 2020 Jun 14]. Available from: https://www. diabetes.or.kr/pro/publish/guide.php?code $=$ guide\&number $=735 \&$ mode $=$ view\#.

47. Katakami N, Mita T, Gosho M, Takahara M, Irie Y, Yasuda T, et al. Clinical utility of carotid ultrasonography in the prediction of cardiovascular events in patients with diabetes: a combined analysis of data obtained in five longitudinal studies. J Atheroscler Thromb 2018;25:1053-66.

48. Cardoso CRL, Salles GC, Leite NC, Salles GF. Prognostic impact of carotid intima-media thickness and carotid plaques on the development of micro- and macrovascular complications in individuals with type 2 diabetes: the Rio de Janeiro type 2 diabetes cohort study. Cardiovasc Diabetol 2019;18:2.

49. Jeevarethinam A, Venuraju S, Dumo A, Ruano S, Mehta VS, Rosenthal M, et al. Relationship between carotid atherosclerosis and coronary artery calcification in asymptomatic diabetic patients: a prospective multicenter study. Clin Cardiol 2017;40:752-8.

50. Akazawa S, Tojikubo M, Nakano Y, Nakamura S, Tamai H, Yonemoto K, et al. Usefulness of carotid plaque (sum and maximum of plaque thickness) in combination with intimamedia thickness for the detection of coronary artery disease 
in asymptomatic patients with diabetes. J Diabetes Investig 2016;7:396-403.

51. Jeevarethinam A, Venuraju S, Dumo A, Ruano S, Rosenthal $\mathrm{M}$, Nair D, et al. Usefulness of carotid plaques as predictors of obstructive coronary artery disease and cardiovascular events in asymptomatic individuals with diabetes mellitus. Am J Cardiol 2018;121:910-6.

52. Jellinger PS, Handelsman Y, Rosenblit PD, Bloomgarden ZT, Fonseca VA, Garber AJ, et al. American Association of Clinical Endocrinologists and American College of Endocrinology guidelines for management of dyslipidemia and prevention of cardiovascular disease: executive summary. Endocr Pract 2017;23:479-97.

53. Arnett DK, Blumenthal RS, Albert MA, Buroker AB, Goldberger ZD, Hahn EJ, et al. 2019 ACC/AHA guideline on the primary prevention of cardiovascular disease: executive summary: a report of the American College of Cardiology/ American Heart Association task force on clinical practice guidelines. Circulation 2019;140:e563-95.

54. Rawshani A, Rawshani A, Franzen S, Sattar N, Eliasson B, Svensson AM, et al. Risk factors, mortality, and cardiovascular outcomes in patients with type 2 diabetes. N Engl $\mathrm{J}$ Med 2018;379:633-44.
55. Seferovic PM, Coats AJS, Ponikowski P, Filippatos G, Huelsmann M, Jhund PS, et al. European Society of Cardiology/Heart Failure Association position paper on the role and safety of new glucose-lowering drugs in patients with heart failure. Eur J Heart Fail 2020;22:196-213.

56. Dunlay SM, Givertz MM, Aguilar D, Allen LA, Chan M, Desai AS, et al. Type 2 diabetes mellitus and heart failure: a scientific statement from the American Heart Association and the Heart Failure Society of America: this statement does not represent an update of the 2017 ACC/AHA/HFSA heart failure guideline update. Circulation 2019;140:e294-324.

57. Seferovic PM, Petrie MC, Filippatos GS, Anker SD, Rosano G, Bauersachs J, et al. Type 2 diabetes mellitus and heart failure: a position statement from the Heart Failure Association of the European Society of Cardiology. Eur J Heart Fail 2018;20:853-72.

58. Yancy CW, Jessup M, Bozkurt B, Butler J, Casey DE Jr, Colvin MM, et al. 2017 ACC/AHA/HFSA focused update of the $2013 \mathrm{ACCF} / \mathrm{AHA}$ guideline for the management of heart failure: a report of the American college of Cardiology/American Heart Association task force on clinical practice guidelines and the Heart Failure Society of America. Circulation 2017;136:e137-61. 